\title{
The Effects of Marine Cloud Brightening on Seasonal Polar Temperatures and the Meridional Heat Flux
}

\author{
Ben Parkes, ${ }^{1}$ Alan Gadian, ${ }^{1}$ and John Latham $^{2,3}$ \\ ${ }^{1}$ NCAS, SEE, University of Leeds, Leeds LS2 9JT, UK \\ ${ }^{2}$ MMM, National Center for Atmospheric Research, Boulder, CO 80307-3000, USA \\ ${ }^{3}$ SEAS, University of Manchester, Manchester M13 9PL, UK \\ Correspondence should be addressed to Alan Gadian, alan@env.leeds.ac.uk \\ Received 27 January 2012; Accepted 19 February 2012 \\ Academic Editors: S. Verma and G. Zhang
}

Copyright ( $) 2012$ Ben Parkes et al. This is an open access article distributed under the Creative Commons Attribution License, which permits unrestricted use, distribution, and reproduction in any medium, provided the original work is properly cited.

\begin{abstract}
Marine cloud brightening (MCB) is one of several proposed solar radiation management (SRM) geoengineering schemes designed to ameliorate some of the undesirable effects of climate change, for example polar ice loss and associated increased sea levels. Satellite measurements over the last 40 years show a general reduction in polar sea ice area and thickness which is attributed to climate change. In our studies, HadGEM1, a fully coupled climate model, is used to predict changes in surface temperatures and ice cover as a result of implementing MCB in a double carbon dioxide concentration atmosphere. The meridional heat flux (MHF) is the mechanism within the earth system for the transport of energy from tropical to polar regions. This poleward transport of heat in a double carbon dioxide atmosphere amplifies the effects in polar regions, where it has a significant impact on both temperatures and ice cover. The results from this work show that MCB is capable of roughly restoring control temperatures and ice cover (where control is defined as $440 \mathrm{ppm}$ carbon dioxide, a predicted 2020 level) in a double carbon dioxide atmosphere scenario. This work presents the first results on the impact of $\mathrm{MCB}$ on the MHF and the ability of the MCB scheme to restore the MHF to a control level.
\end{abstract}

\section{Introduction}

Global warming is a major feature of climate change, and many publications have shown that it is most pronounced at high latitudes with the Arctic and Antarctic showing considerable heating compared to the rest of the world [1]. This additional heating of the polar regions is known as polar amplification and results in temperature changes far above the global average. Several mechanisms have been proposed to explain polar amplification. One is a sea ice-albedo feedback proposed by Curry et al. in 1996 [2]. A reduction of sea ice cover exposes the sea surface, which is of a lower albedo, so that there is more absorption of solar radiation and concomitant additional warming. This heating of polar waters further increases the sea ice loss. The Arctic has been shown to be more susceptible than the Antarctic to changes in temperature; resulting in larger effects in the northern hemisphere [3]. This result is repeated in several papers on $\mathrm{MCB}$ (e.g., $[4-7])$. The work in $[4,7]$ modifies clouds in tropical regions and finds an associated local cooling to $1.5 \mathrm{~m}$ air temperature, however Figure 3 of [4] and Figure 4(d) of [7] show that MCB also preferentially cools the Arctic. The aim of this study is to investigate the preferential cooling of the Arctic and if possible suggest a mechanism to explain how seeding in the tropics leads to a cooling in the Arctic. MCB is one of several proposed Solar Radiation Management (SRM) geoengineering ideas designed to reduce some of the impacts of climate change. MCB utilises the first and second aerosol indirect effects on clouds $([8,9]$, resp.). Exploitation of the first indirect effect is based upon increasing the cloud droplet number concentration (CDNC). A higher number of smaller droplets increase the optical thickness of clouds which therefore reflect more shortwave radiation. The second indirect effect prolongs cloud lifetime as smaller droplets take longer to coalesce into droplets large enough to precipitate out of the clouds.

Several approaches are taken to investigate $\mathrm{MCB}$ and its impacts, from atmosphere only modelling work $[11,12]$, 
TABLE 1: Simulations produced using HadGEM1 to investigate the climate effects of MCB.

\begin{tabular}{lcr}
\hline Experiment name & Carbon dioxide fraction $(\mathrm{ppm})$ & Seeding scheme \\
\hline CON & 440 & None \\
$2 \mathrm{CO} 2$ & $440+1 \% /$ year, held at 560 & None \\
MCB3 & $440+1 \% /$ year, held at 560 & Three regions \\
MCBA & $440+1 \% /$ year, held at 560 & All ocean \\
\hline
\end{tabular}

to coupled atmosphere slab ocean models $[4,6]$, to fully coupled global climate models (GCMs) $[4,5,7,13]$. A GCM is used to compare the effects of seeding three regions of persistent marine stratocumulus clouds individually or as a group $[4,7,13]$. These simulations impose a cloud droplet number concentration (CDNC) of $N=375 \mathrm{~cm}^{3}$ and found that $\mathrm{MCB}$ is capable of substantially reducing the polar impact of increasing carbon dioxide. The impacts of MCB on both annual and seasonal polar ice coverage are investigated in $[5-7,13]$. Previous studies predict an accompanying rainfall reduction in the Amazon region $[4,5,7,13]$, the amount of which varies from model to model. These differences appear to be related to differences in seeding strategy but are not relevant for this paper.

Most GCM studies assume a fixed value for the CDNC and do not assess the technological requirements for attaining this value $[4-7,11,13]$. A seeding mechanism was proposed by Salter et al. in 2008 [14] whereby autonomous GPS guided ships would use solar power to create large numbers of $2 \mathrm{~nm}$ seawater droplets which would act as cloud condensation nuclei. The ships were designed to move perpendicular to trade winds allowing the seawater particles to spread over a large area.

\section{Experiment Description}

HadGEM1-used in our computations - is the Hadley centre Global Environment Model developed by the UK Met Office as version 6.1 of the Unified Model [15]. HadGEM1 is the combination and coupling of the HadGAM and HadGOM atmosphere and ocean models. The model atmosphere has a horizontal resolution of $1.875^{\circ}$ longitude by $1.25^{\circ}$ latitude and 38 vertical levels of increasing size to a maximum height of $39 \mathrm{~km}$ with 10 levels between $0 \mathrm{~km}$ and $2 \mathrm{~km}$. The dynamics and radiation schemes within the atmospheric model are described in [16, 17]. The atmosphere is coupled to an ocean which has a resolution of $1^{\circ}$ square between the poles and $30^{\circ}$. Between $30^{\circ}$ and the equator the meridional resolution of the ocean increases smoothly to $(1 / 3)^{\circ}$. The ocean has 40 smoothly increasing depths, $10 \mathrm{~m}$ near the surface, to $345 \mathrm{~m}$ at $5.3 \mathrm{~km} \mathrm{[18].}$

The model has been modified to have a fixed CDNC in the three regions of low-level marine stratocumulus; these regions are of the coasts of California, Peru and Namibia as shown in Figure 1 of Jones et al. 2009 [4]. The second geoengineering simulation seeds the entire marine atmosphere. In the unseeded regions, and the CON and 2CO2 experiments, the CDNC is unmodified and the original model derivation of CDNC is used. In a modified region the CDNC is set to be $375 \mathrm{~cm}^{3}$ at all model levels between $0 \mathrm{~km}$ and $3 \mathrm{~km}$ and held static for the duration of the simulation. This bypasses the normal method used by the model to calculate the CDNC. The model average CDNC for marine regions at $1 \mathrm{~km}$ is roughly $60 \mathrm{~cm}^{3}$ which is much lower than the $375 \mathrm{~cm}^{3}$ that is used to simulate MCB.

Four cases were run to investigate the effects of MCB on polar temperatures. The setup of the four simulations is shown in Table 1. A comparison of CON and 2CO2 shows the effects of increasing carbon dioxide levels, while comparing $\mathrm{MCB} 3$ or MCBA with 2CO2 shows the differences resulting from seeding. Comparing MCB3 or MCBA with CON shows the combined impacts of increasing carbon dioxide while using MCB. Each simulation was run for 70 years with the final 20 years used for analysis. The initial state for the model was copied from an existing model run that had been simulated between 1860 and 2020 .

\section{Calculation of the Meridional Heat Flux}

Incoming shortwave solar radiation warms the tropics more than the poles, while emitted longwave radiation cools the whole planetary surface. In the absence of a fluid atmosphere or ocean, the only method to balance the earth's surface temperature would be by conduction. With an atmosphere or ocean, transport of energy polewards is possible, and this is defined as the Meridional Heat Flux (MHF). Large-scale dynamics and eddies transport energy polewards as shown analytically and numerically in [19], while the oceanic energy transport is largely driven by the thermohaline circulation and ocean currents. The total MHF can be calculated from the top-of-atmosphere radiative balance $[10,20]$. MHF can be estimated in total or in oceanic and atmospheric components $[10,20]$. In previous work [20] the ERBE dataset was used to find the total MHF with the NCEP and ECMWF models used to find the contribution from the atmosphere and ocean.

The method used to calculate the MHF in this work replicates that used in both Trenberth and Caron 2001 [20], and Wunsch 2005 [10]. The MHF is calculated from monthly average radiative flux difference at the top of the atmosphere. For each latitude band around the globe, the radiative flux difference is summed to give a total flux difference at each band. These total flux differences are then multiplied by the area in each band, to calculate an energy flux out of the atmosphere for each band. The fluxes are then accumulated from the South pole to the North pole with the final sum defining the MHF [10]. 
Figures 1(a) and 1(b) show the annual average radiative balance at the top of the atmosphere from the ERBE dataset and our computed HadGEM1 results. These values are multiplied by the area in each latitude band to give the contribution of each band to the total MHF. To produce Figure 1(d) the data from Figure 1(b) was regridded, from the HadGEM1 model grid to the $2.5^{\circ}$ square grid used by the ERBE dataset. The regridding enables a direct comparison between the results in Figures 1(c) and 1(d). If the original grid spacing were retained the HadGEM results would show a larger number of smaller fluxes. Figure 1(e) shows the summation of the results in Figure 1(c) from the South pole to the North pole. Figure 1(f) is generated using the same method as Figure 1(e) with data that has not been regridded to the lower ERBE resolution. It can be seen that the MHF values derived from HadGEM1 were compared well with the dataset and show less of an imbalance when the calculation direction is reversed from the North to the South.

\section{Results}

The results in Figure 2 show the change in average summer and winter surface temperature and in many cases are reflected in the sea ice fraction plots shown in Figure 3. Figures 3(a) and 3(b) show the effects of doubling atmospheric carbon dioxide concentration on northern polar sea ice fraction. The warming values found in Figures 2(a) and 2(b) agree with those found in Figure 1(a) of [5] and Figure 4(b) of [7] where, again, the doubling of atmospheric carbon dioxide leads to a disproportionate warming in the polar regions. This warming of the climate results in a loss of $3.6 \times 10^{6} \mathrm{~km}^{2}$ of Arctic sea ice and a further $1.0 \times$ $10^{6} \mathrm{~km}^{2}$ of Antarctic sea ice. The global average temperature change between the control and double carbon dioxide concentration atmosphere for the work in [4] is $+0.58 \mathrm{~K}$; in this work the difference is $+0.82 \mathrm{~K}$.

It can be seen in Figures 3(a) and 3(b) that doubling the carbon dioxide concentration causes a greater increase in temperature difference during the winter, than in summer. We find that seeding the three regions results in a global average polar cooling of $0.8 \mathrm{~K}$ as can be seen in Figures 3(c) and $3(\mathrm{~d})$. This cooling acts against the polar amplification and reduces South polar ice loss to $0.79 \times 10^{6} \mathrm{~km}^{2}$ while increasing North polar ice cover by $0.20 \times 10^{6} \mathrm{~km}^{2}$. The results from a comparison between MCBA and CON shown in panels (e) and (f) of Figures 2 and 3, indicate the extensive cooling brought on by all-sea seeding. The majority of the northern hemisphere is subject to a significant reduction in surface temperatures which in turn influences the sea ice coverage. There is however a warming found in the region South of Greenland. Despite this warming, the Arctic sea ice is increased by $2.3 \times 10^{6} \mathrm{~km}^{2}$ and in the Southern hemisphere the increase in sea ice cover is $7.9 \times 10^{6} \mathrm{~km}^{2}$.

We present the first analysis of changes to an MHF as a result of simulating the deployment of MCB in a double carbon dioxide concentration atmosphere. The maximum MHF, in the northern hemisphere, is generally found close to 40 degrees $\mathrm{N}$ and the maximum value from the control,
CON is found to be $5.8 \mathrm{PW}$. The heating from doubling carbon dioxide raises the maximum to $6.1 \mathrm{PW}$ while three region seeding in MCB3 reduces this to 5.7 PW. In MCBA the maximum MHF is reduced to $4.0 \mathrm{PW}$. These results demonstrate how MCB, even when seeding is applied in three-relatively small maritime regions, can cause an appreciable change in the global MHF.

\section{Discussion}

The results from our four climate simulations including two MCB scenarios show a strong connection between sea ice fraction and sea surface temperatures. These two quantities are influenced by a sea ice-albedo feedback loop which in turn is influenced by the MHF, which transports heat energy polewards [21]. Furthermore our control simulation (CON) is in good agreement with previous work on the MHF using the ERBE dataset $[10,20]$. Polar amplification leads to a polar heating and thus a reduction in sea ice which then possibly starts the positive feedback resulting in further heating and sea ice loss. Thus MCB may be able to target polar regions more effectively than other geoengineering methods $[5,11]$. In particular, in the double carbon dioxide scenario, $\mathrm{MCB}$ produces a significant reduction in sea ice loss.

We can see from the results in Figures 2(c), 2(d), 3(c), and $3(d)$ that seeding the selected three regions of stratocumulus clouds returns climate to close to but not exactly the control situation. This agrees with results [5] where different areas of cloud were seeded to a much higher value of $\mathrm{N}$. The ability of MCB to return to close to a control simulation is further reflected in Figure 4 where the MCB3 MHF flux curve is almost overlaid on CON.

The results from a double carbon dioxide atmosphere (no seeding) run are consistent with those of [4-7]. These show that polar regions are warmed significantly more than tropical regions and that this warming has a significant impact upon sea ice cover. When an MCBA seeding scenario is used we see further evidence to support the link between MHF and polar temperatures and also the impact these temperatures have on sea ice fraction. With reduced polar temperatures, ice growth is significant.

This work builds upon previous studies $[4-7,11]$ which show that MCB cannot reproduce the control climate but can return the polar ice state to that similar to the control. There is a need for further studies to understand better the complexities of marine stratocumulus clouds, to assess the consequences of modifying the patterns of polar temperature and sea ice cover, and to thoroughly examine the (possibly adverse) consequences of MCB deployment. The impact of $\mathrm{MCB}$ on precipitation patters has been investigated in several publications $[4-7,13]$. Work in Latham et al. (In press) [13] uses simulations similar to those in Table 1 to assess the impact of three region $\mathrm{MCB}$ on precipitation patterns.

Further work is needed to estimate the relative sizes of the atmospheric and oceanic contributions to the MHF in a geoengineered atmosphere. 


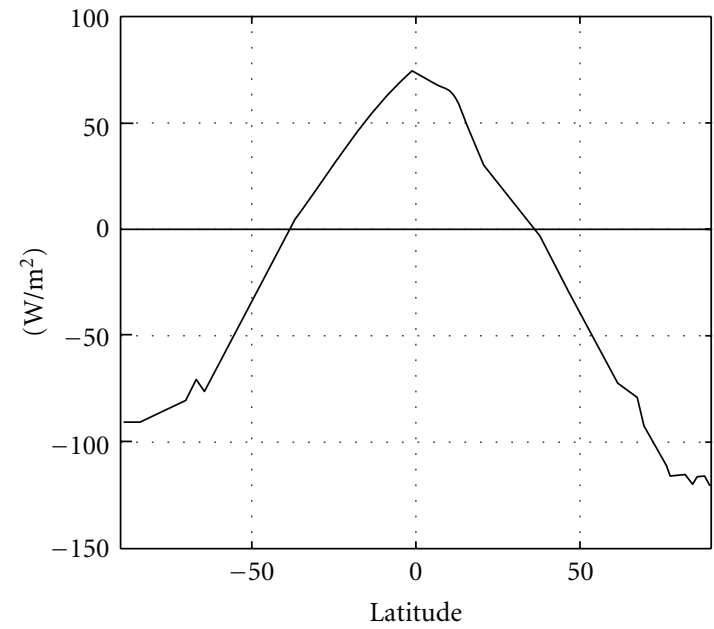

(a)

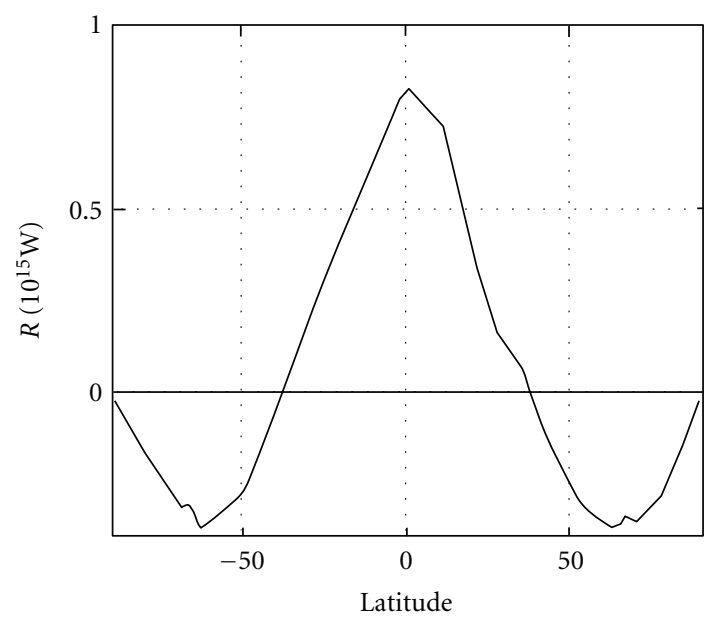

(c)

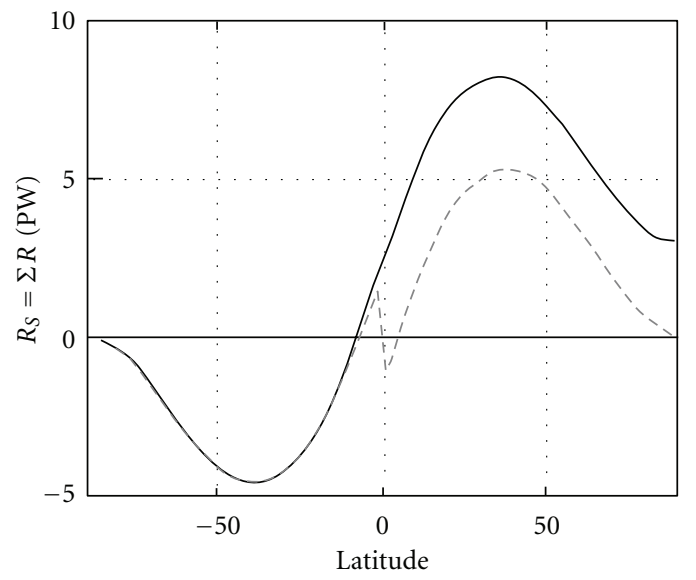

(e)

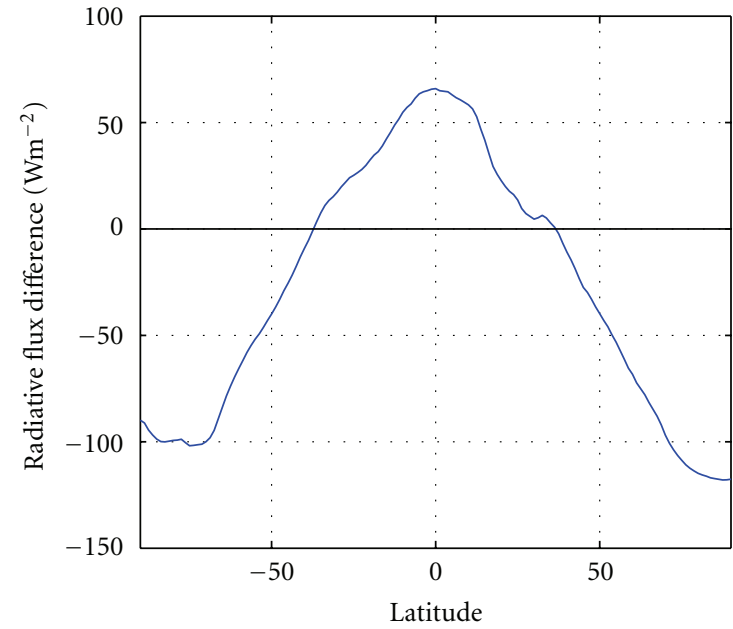

(b)

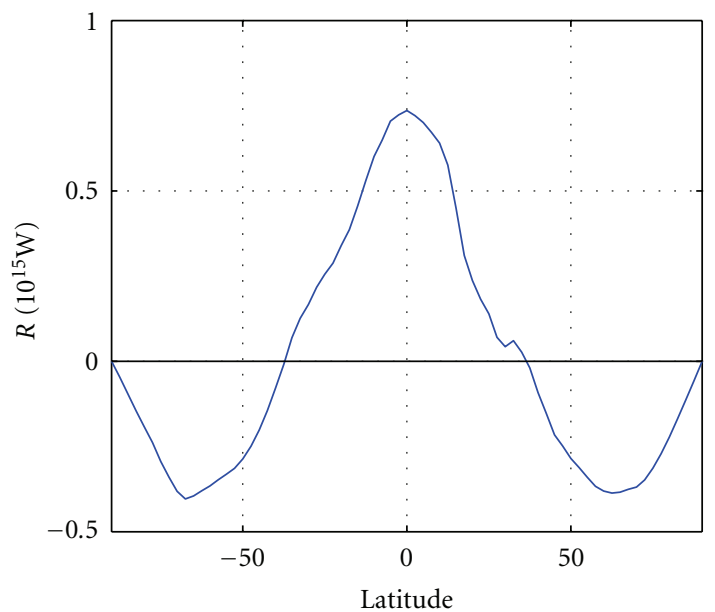

(d)

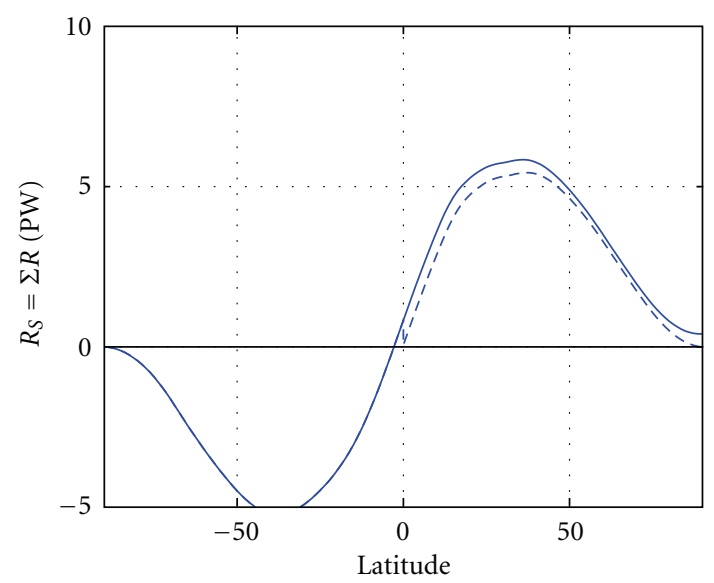

(f)

FIGURE 1: Calculation of the MHF from radiative balance values in the ERBE dataset [10] (left) and HadGEM1 (right). (a) and (b) show the annual average radiative balance. (c) and (d) multiply (a) and (b) by the area in each latitude band. (e) and (f) sum these values from $90^{\circ} \mathrm{S}$ to $90^{\circ} \mathrm{N}$ to give the MHF. Dotted lines in (e) and (f) show the result from $90^{\circ} \mathrm{N}$ to $90^{\circ} \mathrm{S}$. (a), (c), and (e) are copied from Figure 2(a), 2(b), and 2(c) of Wunsch 2005 [10]. 


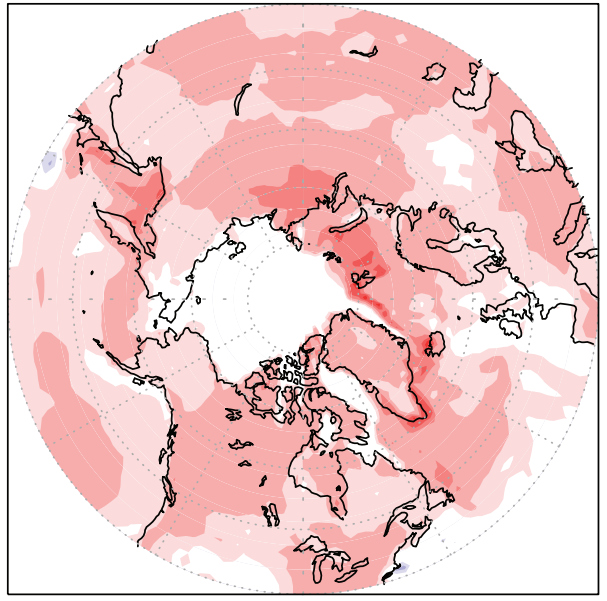

(a)

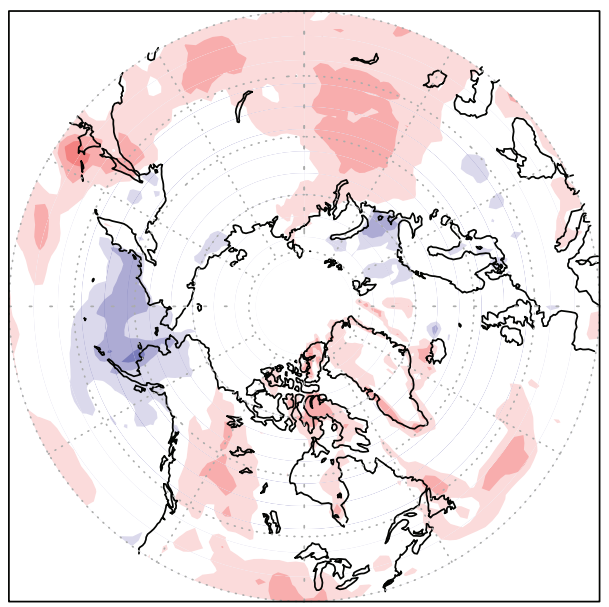

(c)

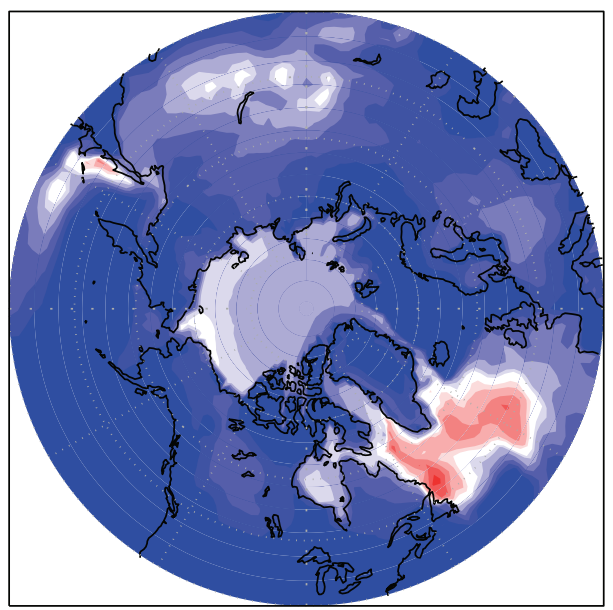

(e)

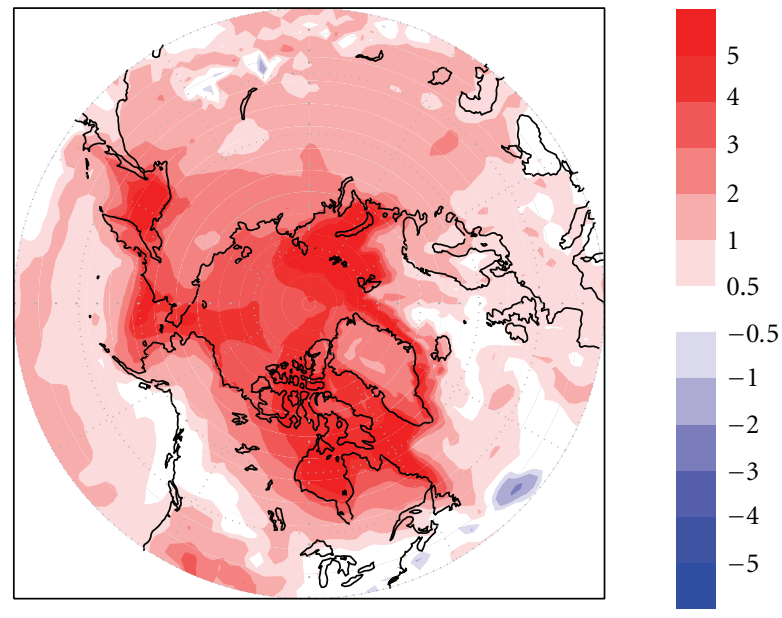

(b)

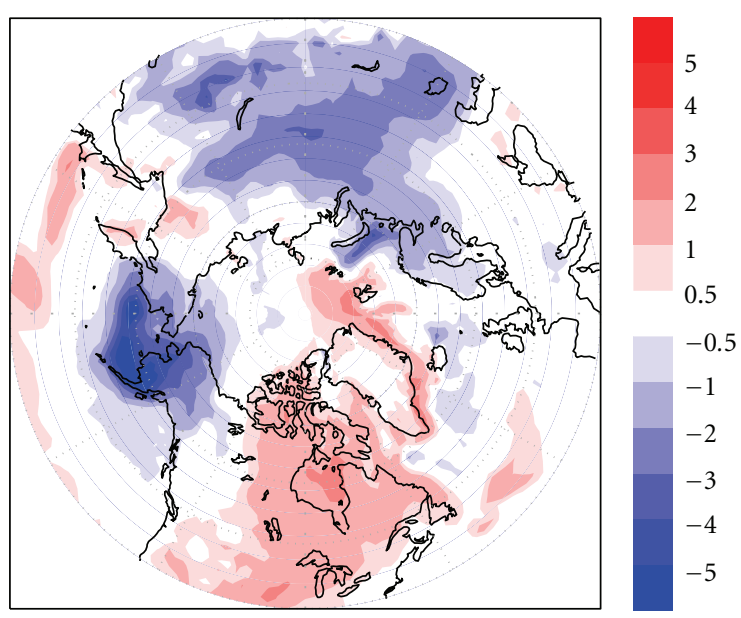

(d)

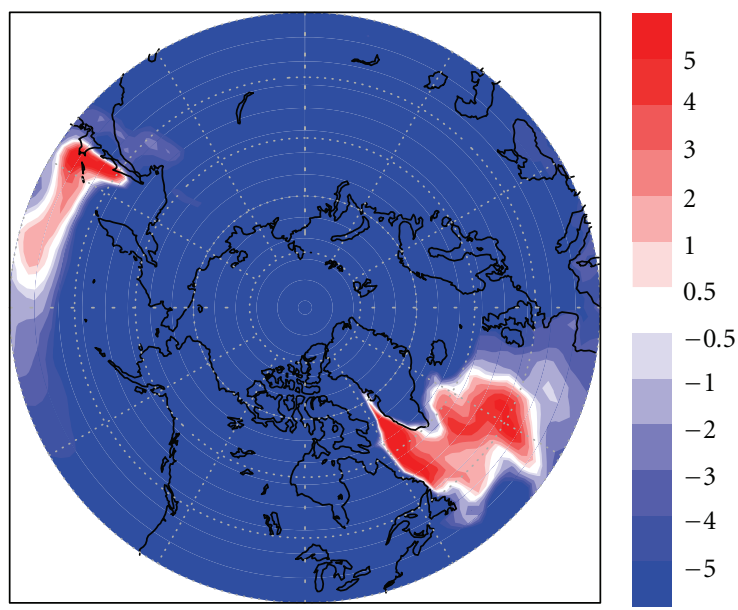

(f)

Figure 2: Comparison of summer (left) and winter (right) polar surface temperatures $(K)$ for four geoengineering simulations. (a) and (b) show the differences between $2 \mathrm{CO} 2$ and CON. (c) and (d) show the differences between MCB3 and CON. (e) and (f) show the differences between MCBA and CON. 


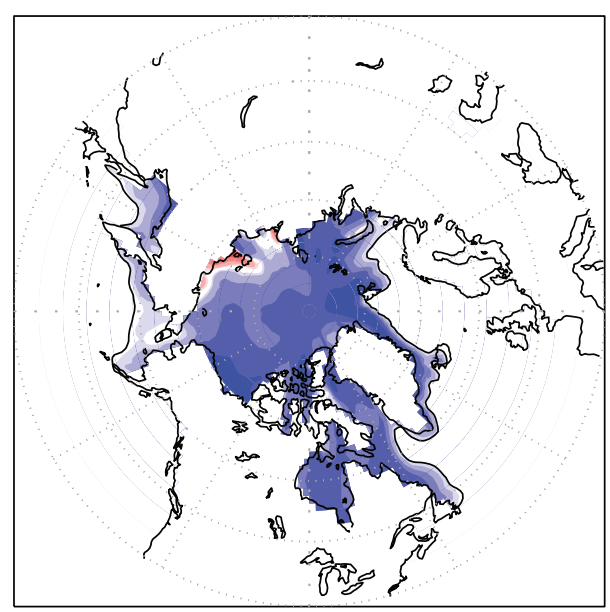

(a)

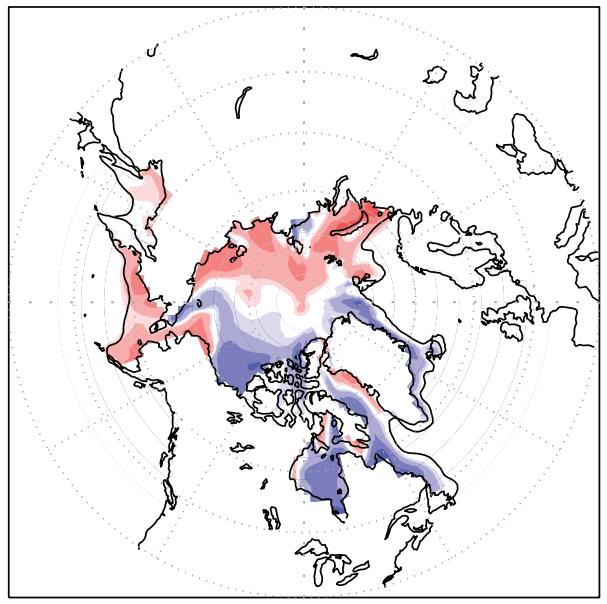

(c)

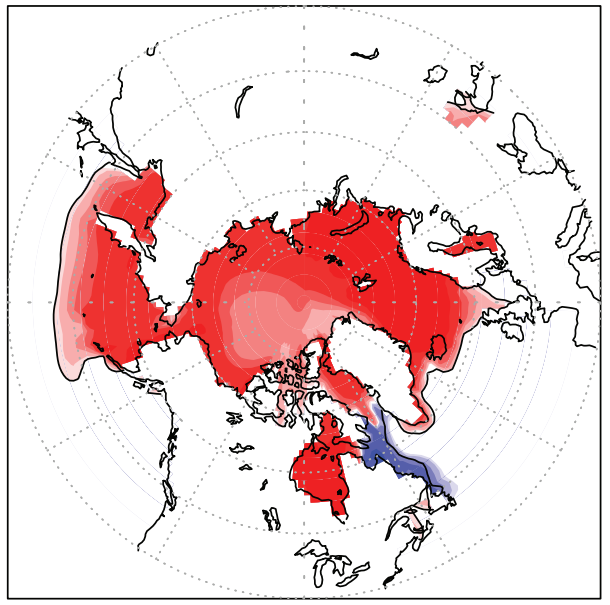

(e)

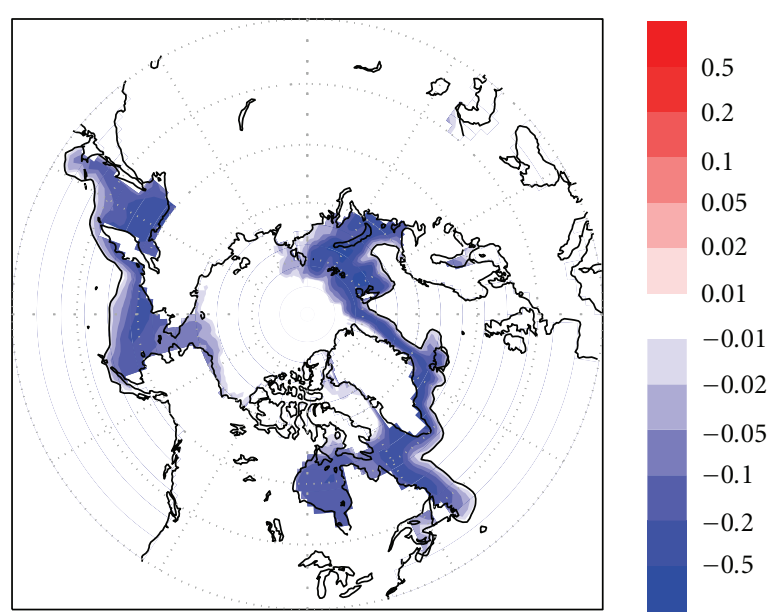

(b)

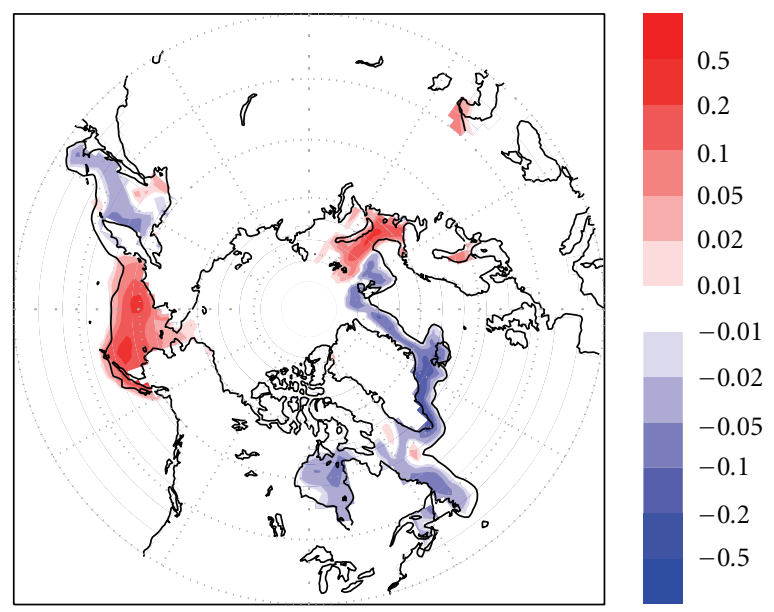

(d)

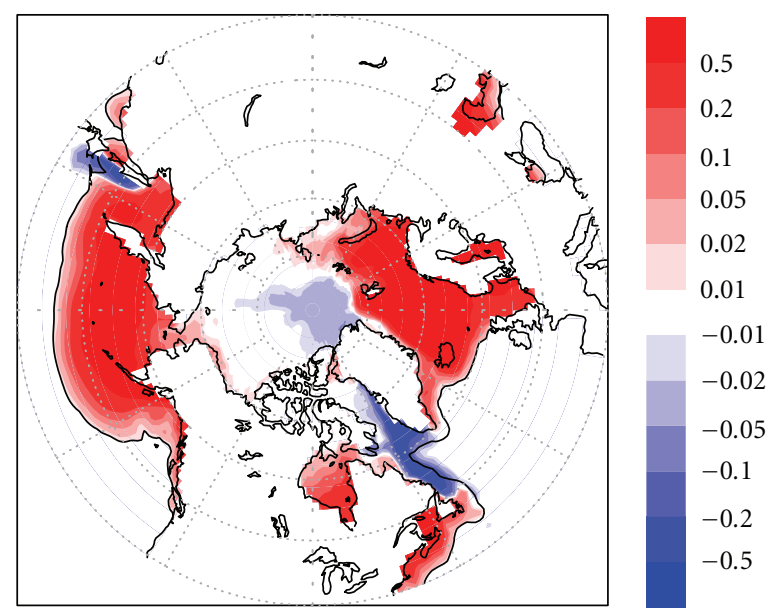

(f)

FIgURE 3: As Figure 2 except for sea ice fraction. The black contour shows the limit of sea ice in the CON simulation. 


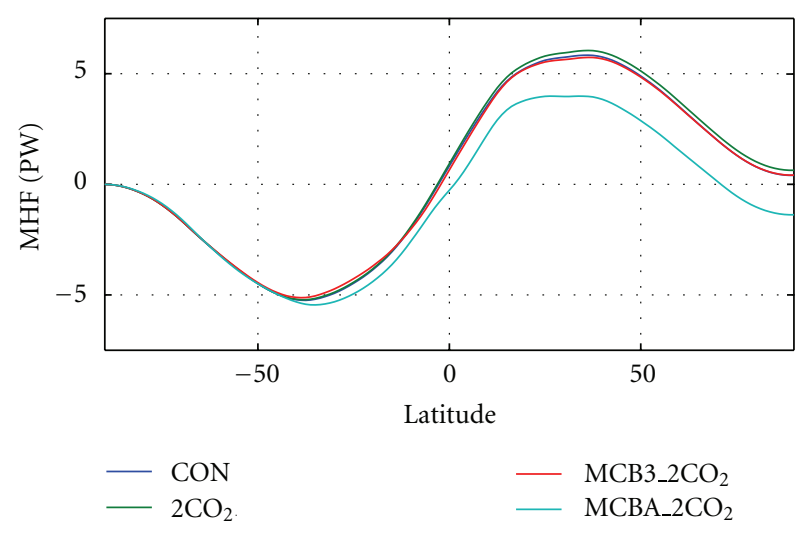

Figure 4: Meridional heat flux for four climate scenarios as described in Table 1.

\section{Acknowledgment}

We are grateful for the use of NERC, NCAS, HECToR supercomputer resources. Support for elements of this research was provided by the Fund for Innovative Climate and Energy Research, FICER, at the University of Calgary. This does not constitute endorsement of deployment in any form of Cloud Albedo Modification by the funding agency.

\section{References}

[1] P. Forster, V. Ramaswamy, P. Artaxo et al., "IPCC synthesis report chapter 2 changes in atmospheric constituents and in radiative forcing climate change 2007: The physical science basis. contribution of working group $i$ to the fourth assessment report of the intergovernmental panel on climate change," in Climate Change 2007: The Physical Science Basis. Contribution of Working Group I to the Fourth Assessment Report of the Intergovernmental Panel on Climate Change, S. Solomon, M. Manning, D. Qin et al., Eds., Cambridge University Press, Cambridge, UK, 2007.

[2] J. A. Curry, W. B. Rossow, D. Randall, and J. L. Schramm, "Overview of arctic cloud and radiation characteristics," Journal of Climate, vol. 9, no. 8, pp. 1731-1764, 1996.

[3] M. M. Holland and C. M. Bitz, "Polar amplification of climate change in coupled models," Climate Dynamics, vol. 21, no. 3-4, pp. 221-232, 2003.

[4] A. Jones, J. Haywood, and O. Boucher, "Climate impacts of geoengineering marinestratocumulus clouds," Journal of Geophysical Research, vol. 114, Article ID D10106, 9 pages, 2009.

[5] P. J. Rasch, J. Latham, and C.-C. J. Chen, "Geoengineering by cloud seeding: influenceon sea ice and climate system," Environmental Research Letters, vol. 4, Article ID 045112, 2010.

[6] G. Bala, K. Caldeira, R. Nemani, L. Cao, G. Ban-Weiss, and H. J. Shin, "Albedo enhancement of marine clouds to counteract global warming: impacts on the hydrological cycle," Climate Dynamics, vol. 37, no. 5-6, pp. 915-931, 2010.

[7] A. Jones, J. Haywood, and O. Boucher, "A comparison of the climate impacts ofgeoengineering by stratospheric so 2 injection and by brightening of marine stratocumulus cloud," Atmospheric Science Letters, vol. 291, no. 2, pp. 176-183, 2011.

[8] S. Twomey, "Pollution and the planetary albedo," Atmospheric Environment, vol. 8, no. 12, pp. 1251-1256, 1974.
[9] B. A. Albrecht, "Aerosols, cloud microphysics, and fractional cloudiness," Science, vol. 245, no. 4923, pp. 1227-1230, 1989.

[10] C. Wunsch, "The total meridional heat flux and its oceanic and atmospheric partition," Journal of Climate, vol. 18, no. 21, pp. 4374-4380, 2005.

[11] J. Latham, P. Rasch, C. C. Chen et al., "Global temperature stabilization via controlled albedo enhancement of low-level maritime clouds," Philosophical Transactions of the Royal Society A: Mathematical, Physical and Engineering Sciences, vol. 366, no. 1882, pp. 3969-3987, 2008.

[12] H. Korhonen, K. S. Carslaw, and S. Romakkaniemi, "Enhancement of marine cloud albedo via controlled sea spray injections: a global model study of the influence of emission rates, microphysics and transport," Atmospheric Chemistry and Physics, vol. 10, no. 9, pp. 4133-4143, 2010.

[13] J. Latham, K. Bower, T. Choularton et al., "Marine cloud brightening," Philosophical Transactionsof the Royal Society A. In press.

[14] S. Salter, G. Sortino, and J. Latham, "Sea-going hardware for the cloud albedo method of reversing global warming," Philosophical Transactions of the Royal Society A: Mathematical, Physical and Engineering Sciences, vol. 366, no. 1882, pp. 39894006, 2008.

[15] G. M. Martin, M. A. Ringer, V. D. Pope, A. Jones, C. Dearden, and T. J. Hinton, "The physical properties of the atmosphere in the new Hadley Centre Global Environmental Model (HadGEM1). Part 1: Model description and global climatology," Journal of Climate, vol. 19, no. 7, pp. 1274-1301, 2006.

[16] T. Davies, M. J. P. Cullen, A. J. Malcolm et al., "A new dynamical core of the Met Office's global and regional modelling of the atmosphere," Quarterly Journal of the Royal Meteorological Society, vol. 131, no. 608, pp. 1759-1782, 2005.

[17] J. M. Edwards and A. Slingo, "Studies with a flexible new radiation code. I: Choosing a configuration for a large-scale model," Quarterly Journal of the Royal Meteorological Society, vol. 122, no. 531, pp. 689-719, 1996.

[18] T. C. Johns, C. F. Durman, H. T. Banks et al., "The new Hadley Centre Climate Model (HadGEM1): Evaluation of coupled simulations," Journal of Climate, vol. 19, no. 7, pp. 1327-1353, 2006.

[19] J. S. A. Green, "Transfer properties of the large-scale eddies and the general circulation ofthe atmosphere," Quarterly journal of the Royal Meteorological Society, vol. 96, pp. 157-185, 1970.

[20] K. E. Trenberth and J. M. Caron, "Estimates of meridional atmosphere and ocean heat transports," Journal of Climate, vol. 14, no. 16, pp. 3433-3443, 2001.

[21] V. A. Alexeev, P. L. Langen, and J. R. Bates, "Polar amplification of surface warming on an aquaplanet in "ghost forcing" experiments without sea ice feedbacks," Climate Dynamics, vol. 24, no. 7-8, pp. 655-666, 2005. 

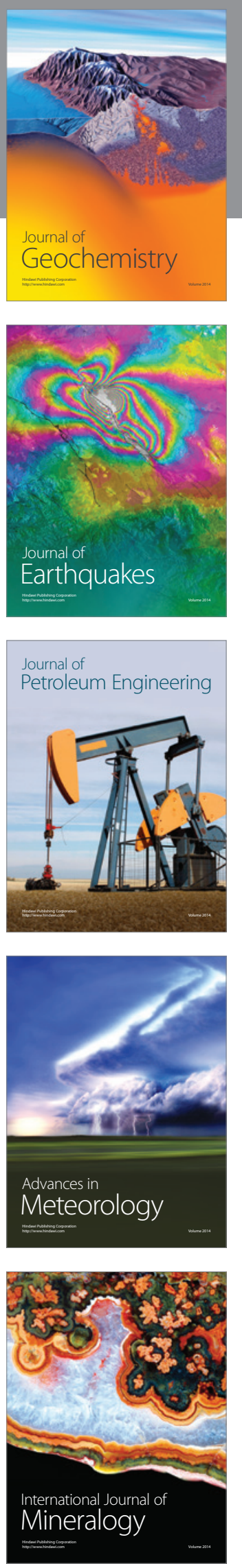
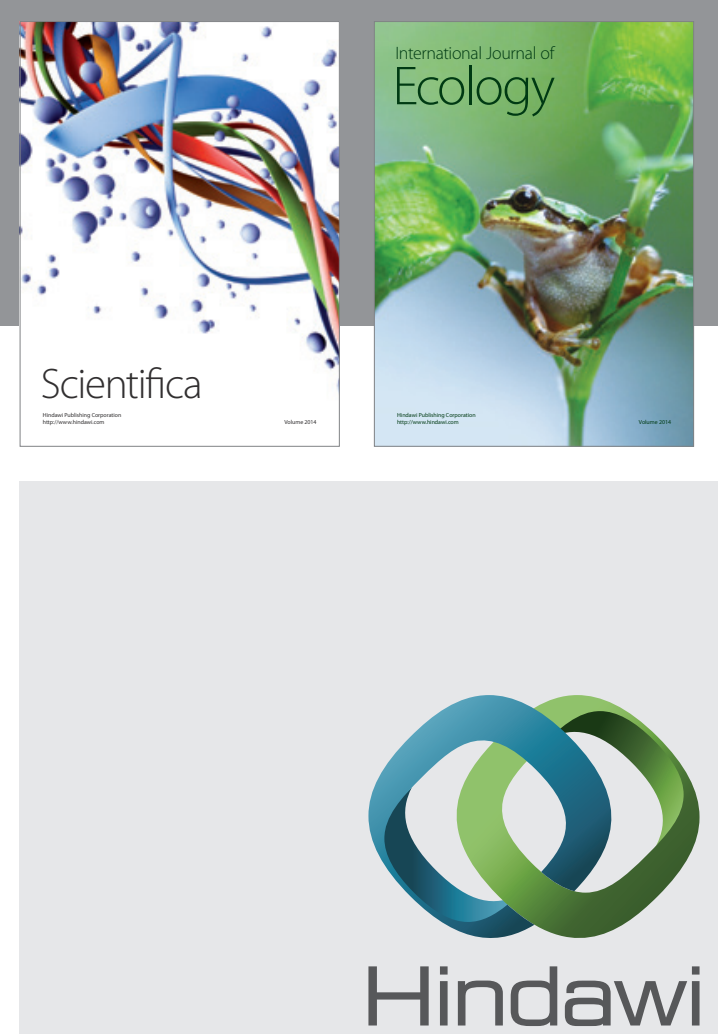

Submit your manuscripts at http://www.hindawi.com
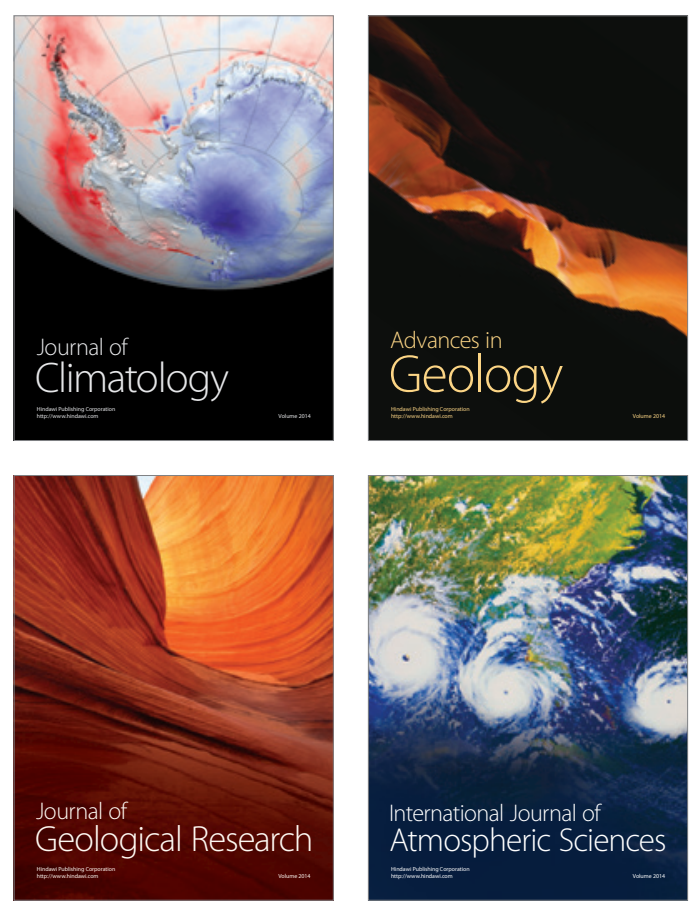
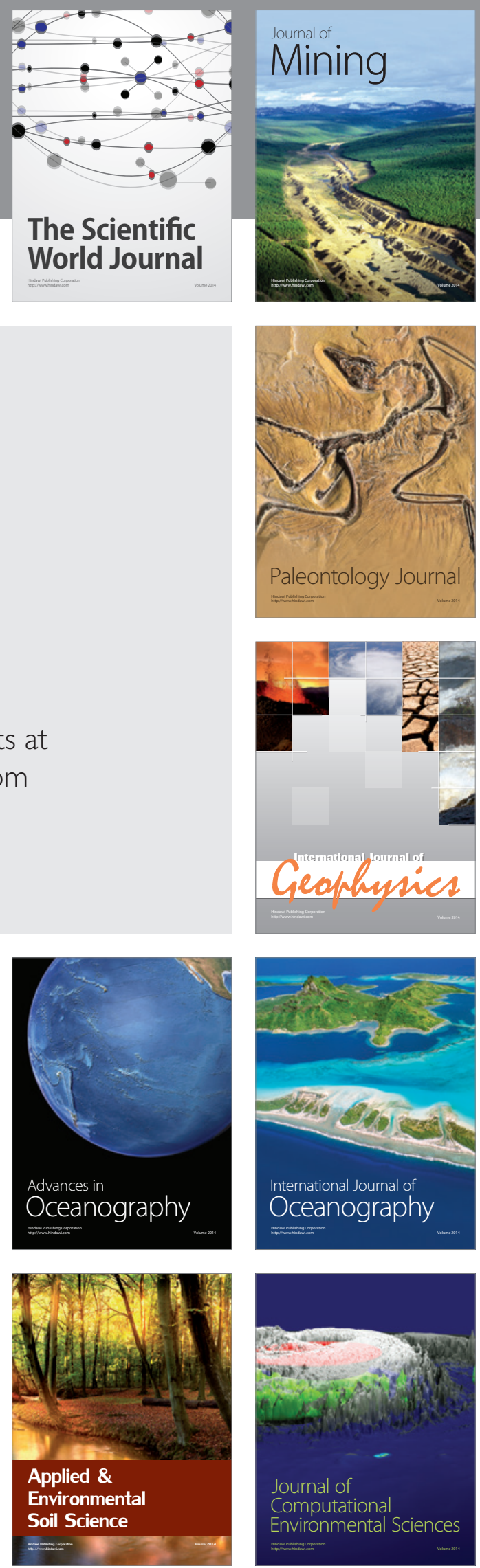